\title{
Determinants of exclusive breastfeeding in infants less than six months of age in Hawassa, an urban setting, Ethiopia
}

\author{
Bethlihem Adugna ${ }^{1 *}$, Henok Tadele ${ }^{2}$, Fekadu Reta ${ }^{3}$ and Yifru Berhan ${ }^{4}$
}

\begin{abstract}
Background: The World Health Organization (WHO) recommends exclusive breastfeeding (EBF) for the first six months of life. However, the proportion of EBF in Ethiopia is 58\%. The EBF practice and factors affecting it have not been studied in Hawassa, Southern Ethiopia. The aim of this study was to assess the prevalence and determinants of EBF practice among infants less than six months age in Hawassa city, Ethiopia.
\end{abstract}

Methods: A total of 529 mothers with infants aged 0-6 months were involved in this study between November 2015 and January 2016. Trained interviewers collected data from the mothers of the infants. Exclusive breastfeeding was assessed based on infant feeding practice in the prior $24 \mathrm{~h}$. Multivariable logistic regression analysis was conducted.

Results: Infants aged 0-5.9 months were studied with comparable gender composition (51.4\% females). The exclusive breastfeeding prevalence was $60.9 \%$ (95\% Cl 56.6, 65.1). Mothers with infants aged 0-1.9 months and 2-3.9 months practiced EBF more likely than mothers with infants aged 4-6 months (Adjusted odds ratio [AOR] 3.59; 95\% $\mathrm{Cl} 2.07,6.2$ ) and (AOR 2.08; 95\% Cl 1.23, 3.5), respectively. Married mothers practiced EBF more likely than singles (AOR 2.04; $95 \% \mathrm{Cl}$ 1.03, 4.06). Housewives practiced EBF more likely than employed mothers (AOR 2.57; 95\% Cl 1.34, 4.9). Mothers who had a vaginal birth were more likely to practice EBF than mothers who gave birth via Cesarean section (AOR 2.8; 95\% $\mathrm{Cl} 1.7,4.6)$. Mothers who gave birth at a healthcare facility were more likely to practice EBF than mothers who gave birth at home (AOR 8.8; 95\% Cl 5.04, 15.4). Mothers without a breast complication practiced exclusive breastfeeding more than mothers with breast complications (AOR 2.05; 95\% Cl 1.5, 4.1).

Conclusions: This study showed a low prevalence of exclusive breastfeeding. Younger infants, babies born to married women, who are housewives, having a vaginal birth in a health facility, and whose mother's breasts were healthy, were predictors for EBF. The promotion of an institutional delivery, optimal breastfeeding practices, and designing strategies to better support employed mothers are recommended.

Keywords: Less than six months of age, Determinants, Ethiopia, Exclusive breastfeeding

\section{Background}

Breast milk is a safe and nutritive diet for the healthy growth and development of infants. The World Health Organization (WHO) recommends exclusive breastfeeding (EBF) for the first six months and continued breastfeeding for two years with the introduction of a complementary diet at six months of age [1]. The prevalence of EBF is below the international

\footnotetext{
* Correspondence: beecho2007@yahoo.com

${ }^{1}$ Addis Ababa city administration Health Department, Kolfe Health Center,

Addis Ababa, Ethiopia

Full list of author information is available at the end of the article
}

recommendation in many countries and worldwide, where only $36 \%$ of children less than six months of age are exclusively breastfed [2, 3].

Exclusive breastfeeding offers short term and long term health benefits both to the mother and the infant $[4,5]$. It also provides economic benefits by reducing both the direct and indirect costs related to healthcare and infant feeding [6]. Non-exclusive breastfeeding is associated with poor academic achievement, and increased morbidity and mortality due to illnesses [7]. According to the recent Ethiopian Demographic and Health Survey (EDHS) report: plain water, non-milk 
liquids or other milk and complementary foods were given to $17 \%, 5 \%$ and $11 \%$ of infants aged $0-5$ months in addition to breast milk, respectively. Breastfeeding used to be universal in Ethiopia but it has now dropped to $76 \%$ at 23 months of age. Only 58\% of infants less than six months of age are exclusively breastfed. The percentage of exclusive breastfeeding decreased sharply with age, from $74 \%$ of infants at $0-1$ month to $36 \%$ of infants at 4-5 months [8].

Several factors can affect the pattern of EBF practice; marital status, wealth index, and child's age were determinant factors for EBF practice, according to the analysis done on the 2005 EDHS raw data [9]. Maternal unemployment and an infant aged less than two months determined EBF practice in a study conducted in South East Ethiopia [10]. A Ghanaian study has revealed higher practices of EBF among mothers who delivered at government health facility compared to mothers who delivered at home or at a private health facility [11].

The government of Ethiopia has initiated several interventions to optimize breastfeeding practices. Health information dissemination using different means, the preparation of training manuals and guidelines are among the intervention strategies. The health extension program, which functions at community level, also operates on infant feeding and nutrition program [12]. Nongovernmental organizations are also addressing the issue of optimal breastfeeding in different regions of the country through advocacy, community mobilization, and mass communication [13]. The prevalence of EBF didn't show a marked improvement despite the interventions. The level and determinant factors for exclusive breastfeeding practices have not been widely studied in southern Ethiopia, and none so far in Hawassa. Hence, the aim of the study was to identify the level of EBF practice and its determinants in Hawassa, southern Ethiopia. The study findings will assist program implementers in designing strategies for the promotion of exclusive breastfeeding in both the study and similar settings.

\section{Methods}

\section{Study area}

The study was conducted in Hawassa Tabor sub-city. Hawassa, the capital of Southern Nations and Nationalities Peoples' Regional State, is located $275 \mathrm{Km}$ south of Ethiopia's capital city Addis Ababa. Hawassa has seven urban sub-cities and one rural sub-city. Tabor sub-city is the second largest sub-city only second to Tulla, a predominantly rural sub-city. Tabor sub-city has a population size of 72,115, with 2159 infants aged 06 months. Hawassa Tabor sub-city has five urban and suburban kebeles (the lowest administration unit in Ethiopia). It has one hospital, twenty clinics, one diagnostic laboratory, seven pharmacies, six medium and four higher level clinics.

\section{Study design}

A community based cross-sectional study was conducted from November 2015 to January 2016 at Hawassa Tabor sub-city, Southern Ethiopia.

\section{Source and study population}

All mothers with infants less than six months of age living in Hawassa Tabor sub-city for over six months were the source population.

\section{Inclusion and exclusion criteria}

All mothers with infants less than six months of age were included in the study. Non-biologic, seriously ill mothers, non-consenting mothers and mothers unable to communicate due to hearing loss were excluded from the study.

\section{Sample size and sampling procedure}

The sample size was calculated by using single population proportion formula by considering EBF prevalence of $49 \%$ [14]. The level of confidence was fixed as $95 \%$ with $4 \%$ margin of error and $15 \%$ nonresponse rate. Hence, the final calculated sample was 541 mothers with infants less than six months of age. All five kebeles in Hawassa Tabor sub-city were involved and the sample was allocated based on population proportion to size. A list of mothers with infants less than six months of age, was available at each kebele and used to identify the study participants by simple random sampling. Pretesting was done on $5 \%$ of the total respondents at a nonparticipating sub-city and kebele of Hawassa city, and adjustments were made to the interview tool accordingly. If the eligible mother was absent during the first visit, a second home visit was done, and if the mother was absent at the second visit, she was considered as non-respondent.

\section{Data collection}

For data collection, pre-tested open-ended and closeended questionnaires were used. Trained data collectors were deployed. Two days training on the data collection tool and procedure was given to eight data collectors and supervisors. Bachelor of Science (BSc) degree graduates in Nursing and Health Officer training were used for data collection and supervision. Completeness was assessed daily by the supervisors.

\section{Operational definitions \\ Exclusive breastfeeding}

Mother breastfed and no other liquids or solids were given, to the child aged less than six months in the 24-h 
prior to the survey, with the exception of oral rehydration solution, supplements or medicines.

\section{Predominant breastfeeding}

The infant's predominant source of nourishment has been breast milk, including milk expressed or feeding from a wet nurse as the predominant source of nourishment. However, the infant may also have received other liquids (water, water-based drinks, fruit juice), ritual fluids and ORS, drops or syrups (vitamins, minerals and medicines).

\section{Partial breastfeeding}

Giving a baby some breastfeeds, and some artificial feeds, either milk or cereal, or other food.

\section{Seriously ill}

Patients who are unconscious and unable to give the required information for this study.

\section{Prelacteal feeding}

Giving infants any drinks except medication or immunization and foods before the initiation of breast milk.

\section{Data analysis}

The questionnaire was checked manually for completeness. Data were entered and analyzed using SPSS windows version 20. Descriptive statistics was computed to determine prevalence of EBF. Logistic regression analysis was carried at two levels to identify factors associated with EBF. First binary logistic regression analysis was carried out and variables with $p$-value $<0.05$ were included in the final multivariable logistic regression analysis. Strength of association was measured using odds ratio and $95 \%$ confidence intervals. The $p$-value $<0.05$ was set for statistical significance.

\section{Results}

\section{Sociodemographic characteristics}

In this study, a total of 529 mother-infant pairs participated, a response rate of $97.8 \%$. The mean maternal age was $25.4 \pm 4.24$ years. Mothers aged 20-29 and 1519 years accounted for 406 (76.7\%) and 29 (5.5\%) of the study subjects, respectively. Infant age ranged from 0 to 5.9 months with mean age of $3.05 \pm 1.56$ months and with comparable gender composition, $51.4 \%$ females. Married mothers constituted 475 (89.8\%) of the study subjects. Maternal education status was found to be 51 (9.6\%) illiterate, 187 (35.3\%) completed primary education, $120(22.7 \%)$ completed secondary education and 171 (32.3\%) completed college and above. More than half of the mothers were multipara 297 (56.1\%), primigravida and grand multipara accounted for 209 (39.5\%) and $23(4.3 \%)$, respectively. The mean family size of the study participants was $4.49 \pm 1.76$. The majority of the mothers were housewives, 303 (57.3\%). More than half, $379(71.6 \%)$ of the household monthly income was less than 1000ETB, (Table 1).

\section{Obstetric and maternal health related characteristics}

Health facility and home deliveries occurred in 414 (78.6\%) and $113(21.4 \%)$ of mothers, respectively. A vaginal birth occurred in 384 (72.6\%) of the mothers. Three hundred thirty two (62.8\%) mothers had antenatal care.

Table 1 Sociodemographic characteristics of respondents in Hawassa Tabor sub-city, 2016

\begin{tabular}{|c|c|c|}
\hline Characteristics & Frequency $(n)$ & Percentage (\%) \\
\hline \multicolumn{3}{|l|}{ Infant gender $(n=529)$} \\
\hline Male & 257 & 48.6 \\
\hline Female & 272 & 51.4 \\
\hline \multicolumn{3}{|l|}{ Infant age $(n=529)$} \\
\hline $0-1.9$ & 193 & 36.5 \\
\hline $2-3.9$ & 203 & 38.4 \\
\hline $4-5.6$ & 133 & 25.1 \\
\hline \multicolumn{3}{|l|}{ Maternal age $(n=529)$} \\
\hline $15-19$ & 29 & 5.5 \\
\hline $20-29$ & 406 & 76.7 \\
\hline $30+$ & 94 & 17.8 \\
\hline \multicolumn{3}{|c|}{ Marital status of the mother $(n=529)$} \\
\hline Married & 475 & 89.8 \\
\hline Single & 54 & 10.2 \\
\hline \multicolumn{3}{|c|}{ Maternal educational status $(n=529)$} \\
\hline Illiterate & 51 & 9.6 \\
\hline Primary education & 187 & 35.3 \\
\hline Secondary education & 120 & 22.7 \\
\hline College and above & 171 & 32.3 \\
\hline \multicolumn{3}{|l|}{ Parity $(n=529)$} \\
\hline Primigravida & 209 & 39.5 \\
\hline Multipara & 297 & 56.1 \\
\hline Grandmultipara & 23 & 4.3 \\
\hline \multicolumn{3}{|l|}{ Family size $(n=529)$} \\
\hline $2-3$ & 184 & 34.8 \\
\hline $4-5$ & 244 & 46.1 \\
\hline Above 5 & 101 & 19.1 \\
\hline \multicolumn{3}{|c|}{ Maternal occupation ( $n=529)$} \\
\hline House wife & 303 & 57.3 \\
\hline Employee & 226 & 42.7 \\
\hline \multicolumn{3}{|l|}{ Monthly income $(n=529)$} \\
\hline$<=1000$ ETB & 150 & 28.4 \\
\hline$>1000$ ETB & 379 & 71.6 \\
\hline
\end{tabular}


Breast complications were reported by 111 (21\%) of the mothers. Painful breasts were the most common reported complication, 56 (50.4\%). From the mothers with breast complication, $18(16.2 \%)$ reported that the problems had interfered with breastfeeding (Table 2).

\section{Infant feeding practices based on $\mathbf{2 4}$ h-recall}

Twenty four hours prior to the interview, other liquids were given to $35.1 \%$ of infants and formula milk, cow's milk, and water accounted for $29.5 \%, 28.5 \%$ and $16.1 \%$, respectively. Semisolids and solids were given to $7 \%$ of the infants. Breast milk only was given to 322 (60.9\%) of the infants. The main reasons for giving other liquids

Table 2 Obstetric and maternal health related characteristics of respondents in Hawassa Tabor sub-city, 2016

\begin{tabular}{|c|c|c|}
\hline Characteristics & $\begin{array}{l}\text { Frequency } \\
(n)\end{array}$ & $\begin{array}{l}\text { Percentage } \\
(\%)\end{array}$ \\
\hline \multicolumn{3}{|l|}{ Place of delivery $(n=529)$} \\
\hline Health facility & 416 & 78.6 \\
\hline Home & 113 & 21.4 \\
\hline \multicolumn{3}{|l|}{ Type of delivery (529) } \\
\hline Normal vaginal & 384 & 72.6 \\
\hline Cesarean section & 145 & 27.4 \\
\hline \multicolumn{3}{|l|}{ Antenatal care $(n=529)$} \\
\hline Yes & 332 & 62.8 \\
\hline No & 197 & 37.2 \\
\hline \multicolumn{3}{|l|}{ Mother sick in last two weeks $(n=529)$} \\
\hline Yes & 74 & 14 \\
\hline No & 455 & 86 \\
\hline \multicolumn{3}{|l|}{ Illnesses $(n=74)$} \\
\hline Back pain & 12 & 16.2 \\
\hline Headache & 6 & 8.1 \\
\hline Abdominal cramp & 42 & 56.8 \\
\hline Others & 14 & 18.9 \\
\hline \multicolumn{3}{|l|}{ Breast complication? $(n=529)$} \\
\hline Yes & 111 & 21.0 \\
\hline No & 418 & 79.0 \\
\hline \multicolumn{3}{|l|}{ Type of breast complication? $(n=111)$} \\
\hline Breast pain & 56 & 50.6 \\
\hline Others & 55 & 50.4 \\
\hline \multicolumn{3}{|l|}{ Breast problems prevent breastfeeding? $(n=111)$} \\
\hline Yes & 18 & 16.2 \\
\hline No & 93 & 83.7 \\
\hline \multicolumn{3}{|l|}{ How did it prevent? $(n=18)$} \\
\hline $\begin{array}{l}\text { Interfered with EBF via early introduction } \\
\text { of other solid/semisolid food }\end{array}$ & 8 & 44.4 \\
\hline Reduced milk production & 10 & 55.5 \\
\hline
\end{tabular}

and semisolid or solid foods were that the child feels hungry, breast milk alone was not enough, and advice from close relatives and others (Table 3).

Table 3 Infant feeding practices based on a 24 h-recall among respondents in Hawassa Tabor sub-city, 2016

\begin{tabular}{|c|c|c|}
\hline Variables & $\begin{array}{l}\text { Frequency } \\
(n)\end{array}$ & $\begin{array}{l}\text { Percentage } \\
(\%)\end{array}$ \\
\hline \multicolumn{3}{|l|}{ Did you give liquids or fluids? $(n=529)$} \\
\hline Yes & 186 & 35.1 \\
\hline No & 343 & 64.8 \\
\hline \multicolumn{3}{|l|}{ Liquids or fluids given? $(n=186)$} \\
\hline Glucose & 3 & 1.6 \\
\hline Boiled water & 30 & 16.1 \\
\hline Formula & 55 & 29.6 \\
\hline Cow's milk & 53 & 28.5 \\
\hline Medication & 1 & 0.5 \\
\hline Others & 44 & 23.6 \\
\hline \multicolumn{3}{|l|}{ Reason for giving liquids/fluids $(n=186)$} \\
\hline Baby felt hungry & 71 & 38.2 \\
\hline Mother producing small milk & 26 & 13.9 \\
\hline Advised by relatives & 26 & 13.9 \\
\hline Advised by health professional & 5 & 2.7 \\
\hline Advised by traditional birth attendant & 5 & 2.7 \\
\hline To treat constipation & 39 & 20.9 \\
\hline Others & 14 & 7.5 \\
\hline \multicolumn{3}{|l|}{ Did you give semisolid/solid? $(n=529)$} \\
\hline Yes & 37 & 7 \\
\hline No & 492 & 93 \\
\hline \multicolumn{3}{|l|}{ Type of semisolid/solid foods? $(n=37)$} \\
\hline Egg & 3 & 8.1 \\
\hline Fruit & 6 & 16.2 \\
\hline Gruel & 5 & 13.5 \\
\hline Mashed potato & 8 & 21.6 \\
\hline Porridge & 13 & 35.1 \\
\hline Others & 2 & 5.4 \\
\hline \multicolumn{3}{|c|}{ Reason for giving semisolid/solid foods? $(n=37)$} \\
\hline Baby was hungry & 23 & 62.1 \\
\hline Mother's breast milk not enough & 3 & 8.1 \\
\hline Advised by relatives & 2 & 5.4 \\
\hline Advised by health professional & 1 & 2.7 \\
\hline Advice by traditional birth attendant & 3 & 8.1 \\
\hline To treat constipation & 5 & 13.5 \\
\hline \multicolumn{3}{|c|}{ Breastfeeding category based on the $24 \mathrm{~h}$ recall $(n=529)$} \\
\hline Exclusively breastfeeding & 322 & 60.9 \\
\hline Predominantly breastfeeding & 65 & 12.3 \\
\hline Partial breastfeeding & 142 & 26.8 \\
\hline
\end{tabular}




\section{Prevalence of exclusive breastfeeding practice}

Based on 24-h recall, the prevalence of EBF was $60.9 \%$ (95\% CI 56.6, 65.1). The age specific prevalence of EBF was $42.9 \%, 39.1 \%$ and $18 \%$ at $1-1.9$ months, 23.9 months, and 4-5.9 months, respectively. Predominant and partial breastfeeding was practiced in $12.3 \%$ and $26.8 \%$ of mothers, respectively.

\section{Knowledge and sources of information on breastfeeding}

The majority of the mothers (80.7\%) received counseling on breastfeeding. Breastfeeding counseling was obtained from health facilities, mass media, families or friends in $62.8 \%, 13.2 \%$ and $6.2 \%$ of the mothers, respectively. Breastfeeding counseling during antenatal, natal, and postnatal periods was obtained in $40.4 \%, 7 \%$ and $15.5 \%$, respectively.

The majority of the mothers $(96.4 \%)$ reported that breastfeeding protects the baby from illness. When asked about the timing of feeding, 95.1\% replied that breastfeeding should be the baby's first food and semisolid/solid food should be introduced to the baby at six months of age. Concerning knowledge, 92.1\% mothers reported that EBF could sustain a baby in a healthy condition for six months. Mothers (60.4\%) reported that expressed breast milk is safe to feed to the baby when the mother is away.

\section{Factors associated with exclusive breastfeeding practices}

Binary logistic regression analysis was done to select variables having association with EBF practice, and twelve variables were selected for final model analysis. Infant age, marital status, maternal occupation, place of birth, mode of delivery and presence of breast complication were significantly associated with EBF practice among infants less than six months of age in multivariable logistic regression analysis.

The practice of EBF among infants aged 0-1.9 months and 2-3.9 months was 3.59 times $(95 \% \mathrm{CI} 2.07,6.2)$ and 2.08 times $(95 \%$ CI 1.23, 3.5) more likely than those infants aged 4-6 months, respectively. Married mothers practiced EBF 2.04 times more likely than single mothers (95\% CI 1.03, 4.06). Housewives practiced EBF 2.57 times more likely than employed mothers (95\% CI 1.34, 4.9).

Mothers who gave birth at a health facility practiced exclusive breastfeeding 8.8 times more than (AOR 8.8; $95 \%$ CI 5.04 , 15.4) mothers who gave birth at home. Mothers who gave birth naturally exclusively breastfed their infants 2.8 times more likely than (AOR 2.8; 9\% CI 1.7, 4.6) mothers with Cesarean section. Concerning breast complications, mothers with no breast complication practiced EBF 2.5 times more likely than (AOR 2.5; $95 \%$ CI 1.5, 4.1) mothers with breast complications (Table 4).

\section{Discussion}

The prevalence of EBF in this study was $60.9 \%$. This is higher than a study done in Bahirdar, (50.3\%) [15], and lower than studies done in Goba district $(71.3 \%)$ and Tigray region (70.2\%) in Ethiopia [10, 16]. This result is far from Ethiopia's fifth Health Sector Development program (HSDP IV) set target, of 70\% [17]. Inclusion of urban and rural setting in the above studies and cross cultural differences could have attributed to the difference. The recall since birth method used to determine exclusive breastfeeding in the Bahirdar study might have underestimated the EBF prevalence.

In our study, the practice of exclusive breastfeeding was associated with infant age. The practice of EBF decreased significantly, close to six months of age, this is in agreement with studies conducted in Brazil, Nigeria and Ethiopia [9, 18-20]. The traditional postpartum family care given in the first few months when mothers remain at home, might encourage exclusive breastfeeding [9]. Complementary feeding might be introduced to infants with the assumption that breast milk alone will not satisfy the need of infant as they approach six months of age.

In the present study, housewives practiced EBF more than employed mothers and this is similar to studies done in Malaysia, Sudan and Ethiopia [21-23]. Early return of employed mothers to the office, lack of support from the office and short maternity leave (only three months paid leave in Ethiopian case) could also discourage employed mothers.

Concerning the place of delivery, mothers who delivered at health facilities practiced EBF more likely than mothers who delivered at home. This is similar to studies done in Ghana, Tanzania, and Nigeria [11, 24, 25]. A Canadian study revealed the opposite results and the negative effect of formula supplementation in their setting was pointed out as the reason [26]. Our finding reinforces the international recommendation of making health facilities 'baby-friendly' as information received from healthcare facilities is welcomed by parents and society.

In this study, more mothers who gave birth naturally practiced exclusive breastfeeding compared to mothers following a Caesarian section delivery. This finding is similar to studies done in Canada, Nepal, and Ethiopia $[15,26,27]$. The effects of Caesarian section on maternal and fetal stress response and disrupted lactogenesis especially in the first 12 weeks postpartum, are reported as a cause for an unsuccessful first breastfeeding attempt and inability to breastfeed upon leaving the healthcare facility [28]. Earlier discharge from the healthcare facility of mothers who had a vaginal birth and their reattachment with families could make the postpartum care smooth and increase chances of EBF. 
Table 4 Determinants of EBF practice among mothers with infants less than 6 months of age in Hawassa Tabor Sub-city, 2016

\begin{tabular}{|c|c|c|c|c|}
\hline Variables & EBFn (\%) & NEBF $n(\%)$ & Crude odds ratio (95\% Cl) & Adjusted odds ratio $(95 \% \mathrm{Cl})$ \\
\hline \multicolumn{5}{|l|}{ Infant gender $(n=529)$} \\
\hline Male & $169(52.5)$ & $88(42.5)$ & $1.49(1.05,2.1)^{*}$ & $1.41(0.92,2.15)$ \\
\hline Female & $153(47.5)$ & $119(57.5)$ & 1 & 1 \\
\hline \multicolumn{5}{|c|}{ Infant age in months $(n=529)$} \\
\hline $0-1.9$ & $138(42.9)$ & $55(26.6)$ & $3.24(2.04,5.15)^{* *}$ & $3.59(2.07,6.2)^{* *}$ \\
\hline $2-3.9$ & $126(39.1)$ & $77(37.2)$ & $2.11(1.35,3.3)^{*}$ & $2.08(1.23,3.5)^{*}$ \\
\hline $4-5.9$ & $58(18)$ & $75(36.2)$ & 1 & 1 \\
\hline \multicolumn{5}{|l|}{ Marital status $(n=529)$} \\
\hline Married & $298(92.5)$ & $177(85.5)$ & $2.1(1.19,3.71)^{*}$ & $2.04(1.03,4.06)^{*}$ \\
\hline Single & $24(7.5)$ & $30(14.5)$ & 1 & 1 \\
\hline \multicolumn{5}{|c|}{ Maternal education status $(n=529)$} \\
\hline Illiterate & $31(9.6)$ & $20(9.7)$ & $1.46(0.7,2.7)$ & $1.44(0.57,3.62)$ \\
\hline Primary education & $124(38.5)$ & $63(30.4)$ & $1.85(1.2,2.8)^{*}$ & $1.50(0.79,2.85)$ \\
\hline Secondary education & $79(24.5)$ & $41(19.8)$ & $1.81(1.12,2.9)^{*}$ & $1.09(0.55,2.16)$ \\
\hline College and above & $88(27.3)$ & $83(40.1)$ & 1 & 1 \\
\hline \multicolumn{5}{|c|}{ Maternal occupation ( $n=529$ ) } \\
\hline Housewife & $208(64.6)$ & $95(45.9)$ & $2.15(1.5,3.07)^{* *}$ & $2.57(1.34,4.9)^{*}$ \\
\hline Employee & $114(35.4)$ & $112(54.1)$ & 1 & \\
\hline \multicolumn{5}{|c|}{ Maternal income source $(n=357)$} \\
\hline Salary & $71(22)$ & $65(31.4)$ & 1 & 1 \\
\hline Husband & $19(59.3)$ & $100(48.3)$ & $1.74(1.15,2.64)^{*}$ & $0.83(0.39,1.77)$ \\
\hline Self-business & $60(18.6)$ & $42(20.3)$ & $1.3(0.77,2.19)$ & $1.31(0.63,2.7)$ \\
\hline \multicolumn{5}{|l|}{ Place of delivery $(n=529)$} \\
\hline Home & $33(10.2)$ & 80 (38.6) & 1 & 1 \\
\hline Health facility & $289(89.8)$ & $127(61.4)$ & $5.5(3.4,8.7)^{* *}$ & $8.8(5.04,15.4)^{* *}$ \\
\hline \multicolumn{5}{|l|}{ Type of delivery $(n=529)$} \\
\hline Normal vaginal & $249(77.3)$ & $135(65.2)$ & $1.81(1.23,2.6)^{*}$ & $2.8(1.7,4.6)^{* *}$ \\
\hline Caesarian section & $73(22.7)$ & $72(34.8)$ & 1 & 1 \\
\hline \multicolumn{5}{|c|}{ Breast complication $(n=490)$} \\
\hline Yes & $45(14)$ & $66(31.9)$ & 1 & 1 \\
\hline No & $289(89.8)$ & $90(43.5)$ & $2.88(1.87,4.42)^{*}$ & $2.5(1.5,4.1)^{* *}$ \\
\hline \multicolumn{5}{|c|}{ BF is alone enough for six months } \\
\hline Yes & $307(95.3)$ & $12(5.8)$ & $3.00(1.59,5.9)^{*}$ & $2.57(1.34,4.9)^{*}$ \\
\hline No & $15(4.7)$ & $180(87)$ & 1 & 1 \\
\hline \multicolumn{5}{|c|}{ Information on optimal breastfeeding $(n=529)$} \\
\hline Yes & $278(86.3)$ & $149(72)$ & $2.45(1.58,3.8)^{* *}$ & $1.66(0.85,3.25)$ \\
\hline No & $44(13.7)$ & $58(28)$ & 1 & 1 \\
\hline \multicolumn{5}{|l|}{ Antenatal care $(n=529)$} \\
\hline No & $101(31.4)$ & $96(46.4)$ & 1 & 1 \\
\hline Yes & 221 (68.6) & $111(53.6)$ & $1.89(1.31,2.7)^{*}$ & $0.92(0.53,1.6)$ \\
\hline
\end{tabular}

$\left.{ }^{*} p<0.05\right) \mathrm{s} p<0.001$

$1=$ reference; $E B F=$ exclusive breastfeeding; $N E B F=$ Nonexclusive breastfeeding; $C l=$ Confidence interval 
In the current study, the presence of breastfeeding complications was associated with EBF practice. This finding is in agreement with a study done in Mauritius [29]. An Indian study has documented the absence of any association between breast problems and EBF, however it was done at single healthcare facility [30]. Our finding underscores the need for proper education on optimal breastfeeding techniques and practices to avoid breast problems and the subsequent impact on exclusive breastfeeding. Though our method of EBF assessment has no recall bias, it may overestimate the rate of exclusive breastfeeding $[31,32]$.

\section{Conclusion}

This study showed a low prevalence of exclusive breastfeeding. Being a younger infant, born to a married woman, who was a housewife, a vaginal birth in a health facility, and healthy mother's breast were determinant factors for EBF. The promotion of a health facility and vaginal birth, optimal breastfeeding practices, and strategies designed to better support employed mothers are recommended.

\section{Abbreviations}

AOR: Adjusted odds ratio; Cl: Confidence interval; COR: Crude odds ratio; EBF: Exclusive breastfeeding; EDHS: Ethiopian demographic health survey; ETB: Ethiopian birr; HSDP/HSTP: health sector development/transformation program/plan; NEBF: Non - exclusive breastfeeding; SNNPR: Southern Nations and Nationalities People's Regional State; SPSS: Statistical package for social science; WHO: World Health Organization

\section{Acknowledgements}

We would like to thank College of Agriculture, Hawassa University for administrative and technical support. We are grateful to Engine project for financial support. Our special thanks go to the study participants for their willingness and to Hawassa Tabor sub-city administration for facilitation.

\section{Funding}

Empowering New Generations to Improve Nutrition and Economic opportunity (ENGINE project), which is funded by United States Agency for International Development (USAID) and Save the Children.

\section{Availability of data and materials}

The datasets analyzed during the current study are available from the corresponding author on reasonable request.

\section{Authors' contributions}

BA: Prepared the proposal, monitored data collection, entered and analyzed data, and wrote up the report; $\mathrm{HT}$ : Reviewed the study plan, data analysis and contributed in the report write up; FA: Reviewed the study plan, data analysis and contributed in the report write up; YB: Made critical contribution in the design, analysis and interpretation of findings. All authors read and approved the final manuscript.

\section{Ethics approval and consent to participate}

Ethical clearance was obtained from institutional review board of College of Medicine and Health Sciences, Hawassa University with IRB Ref no. 076/07. Written permission was obtained from Hawassa Tabor sub-city administration and each kebele was approached thereafter. Informed oral and written consent was obtained from each participant after adequate information is provided. Participants were informed of their right to voluntary participation and the right to withdraw from the study at any time, without having any punishment, which protects their right to self- determination. Data obtained within the study were treated as confidential and stored securely.
Consent for publication

Not applicable.

\section{Competing interests}

The authors declare that they have no competing interests.

\section{Publisher's Note}

Springer Nature remains neutral with regard to jurisdictional claims in published maps and institutional affiliations.

\section{Author details}

${ }^{1}$ Addis Ababa city administration Health Department, Kolfe Health Center, Addis Ababa, Ethiopia. ${ }^{2}$ Department of Pediatrics and Child Health, College of Medicine and Health Sciences, Hawassa University, Hawassa, Ethiopia. ${ }^{3}$ School of Nutrition, College of Agriculture, Hawassa University, Hawassa, Ethiopia. ${ }^{4}$ Department of Obstetrics and Gynecology, College of Health Sciences, Addis Ababa University, Addis Ababa, Ethiopia.

Received: 21 April 2017 Accepted: 25 October 2017

Published online: 02 November 2017

\section{References}

1. World Health Organization. Infant and young child feeding (IYCF) model chapter for textbooks for medical students and allied health professionals. Switzerland: world health Organization. 2009:

2. United Nations Children's Fund (UNICEF). Breastfeeding on the worldwide agenda: findings from a landscape analysis on political commitment for programmes to protect, promote and support breastfeeding. In: United Nations Children's fund; 2013.

3. Haider R, Saha KK. Breastfeeding and infant growth outcomes in the context of intensive peer counselling support in two communities in Bangladesh. Int Breastfeed J. 2016;11:18.

4. Lutter C, Ross J, Martin L, León-Cava N. Quantifying the benefits of breastfeeding: a summary of the evidence. Washington DC: pan American health Organization. 2002;

5. Cames C, Saher A, Ayassou KA, Cournil A, Meda N, Simondon KB. Acceptability and feasibility of infant-feeding options: experiences of HIVinfected mothers in the world health organization Kesho bora mother-tochild transmission prevention (PMTCT) trial in Burkina Faso. Matern Child Nutr. 2010;6(3):253-65.

6. Weimer J. The economic benefits of breastfeeding: a review and analysis. Food and rural economics division, Economic Research Service, U.S. Department of Agriculture. Food assistance and nutrition research report no. 13. Washington dc. 2001;

7. World Health Organization. Global strategy for infant and young child feeding. In: The optimal duration of exclusive breastfeeding. Geneva: World health organization; 2001.

8. Central Statistical Agency (CSA) [Ethiopia] and ICF. 2016. Ethiopia demographic and health survey 2016: key indicators report. Addis Ababa, Ethiopia and Rockville, Maryland, USA. CSA and ICF.

9. Alemayehu T, Haidar J, Habte D. Determinants of exclusive breastfeeding practices in Ethiopia. Ethiop J Health Dev. 2009;23(1):12-8.

10. Setegn T, Belachew T, Gerbaba M, Deribe K, Deribew A, Biadgilign S. Factors associated with exclusive breastfeeding practices among mothers in Goba district, south east Ethiopia: a cross-sectional study. Int Breastfeed J. 2012;7:17

11. Tampah-Naah AM, Kumi-Kyereme A. Determinants of exclusive breastfeeding among mothers in Ghana: a cross-sectional study. Int Breastfeed J. 2013;8:13.

12. Fetene $\mathrm{N}$, Linnander $\mathrm{E}$, Fekadu B, Alemu $\mathrm{H}$, Omer $\mathrm{H}$, Canavan $\mathrm{M}$, Smith J, Berman P, Bradley E. The Ethiopian health extension program and variation in health systems performance: what matters? PLoS One. 2016;1 1:5.

13. Kim SS, Rawat R, Mwangi EM, Tesfaye R, Abebe Y, Baker J, Frongillo EA, Ruel MT, Menon P. Exposure to large-scale social and behavior change communication interventions is associated with improvements in infant and young child feeding practices in Ethiopia. PLoS One. 2016;11:10.

14. Sefene A, Birhanu D, Awoke W, Taye T. Determinants of exclusive breastfeeding practice among mothers of children age less than 6 month in Bahir Dar city administration, northwest Ethiopia; a community based cross-sectional survey. Sci J Clin Med. 2013;2(6):153-9. 
15. Seid AM, Yesuf ME, Koye DN. Prevalence of exclusive breastfeeding practices and associated factors among mothers in Bahir Dar city, northwest Ethiopia: a community based cross-sectional study. Int Breastfeed J. 2013:8:14.

16. Teka B, Assefa H, Haileslassie K. Prevalence and determinant factors of exclusive breastfeeding practices among mothers in Enderta woreda, Tigray, north Ethiopia: a cross-sectional study. Int Breastfeed J. 2015;10:2.

17. The Federal Democratic Republic of Ethiopia Ministry of Health. Health sector transformation plan 2015/16-2019/20. Addis Ababa: Federal ministry of Health-Ethiopia; 2015.

18. De Gusmao AM, Béria JU, Gigante LP, Leal AF, Schermann LB. Prevalence of exclusive breastfeeding and associated factors: a cross-sectional study with adolescent mothers from 14 to 16 in Porto Alegre, Brazil. Cien Saude Colet. 2013;18(11):3357-68.

19. Lawoyin TO, Olawuyi JF, Onadeko MO. Factors associated with exclusive breastfeeding in Ibadan, Nigeria. J Hum Lact. 2001;17(4):321-5.

20. Seifu W, Assefa G, Egata G. Prevalence of exclusive breast feeding and its predictors among infants aged six months in limma town, southwest Ethiopia. J Pediatr Neonatal Care. 2013;1:17.

21. Tan KL. Factors associated with exclusive breastfeeding among infants under six months of age in peninsular Malaysia. Int Breastfeed J. 2011;6:2.

22. Haroun HM, Mahfouz MS, Ibrahim BY. Breast feeding indicators in Sudan: a case study of wad Medani town. Sudanese Aust J Public Health. 2008:3(2):81-9.

23. Yeneabat T, Belachew T, Haile M. Determinants of cessation of exclusive breastfeeding in Ankesha Guagusa woreda, Awi zone, northwest Ethiopia: a cross-sectional study. BMC Pregnancy Childbirth. 2014;14:262.

24. Nkala TE, Msuya SE. Prevalence and predictors of exclusive breastfeeding among women in Kigoma region, western Tanzania: a community based cross-sectional study. Int Breastfeed J. 2011;6:17.

25. Ukegbu AU, Ebenebe EU, Ukegbu PO. Breastfeeding pattern, anthropometry and health status of infants attending child welfare clinics of a teaching hospital in Nigeria. South Afr J Clin Nutr. 2010;23(4):191-6.

26. Al-Sahab B, Lanes A, Feldman M, Tamim H. Prevalence and predictors of 6-month exclusive breastfeeding among Canadian women: a national survey. BMC Pediatr. 2010;10:20.

27. Chandrashekhar TS, Joshi HS, Binu V, PR Shankar PR, Rana MS, Ramachandran U. Breast-feeding initiation and determinants of exclusive breast-feeding - a questionnaire survey in an urban population of western Nepal. Public Health Nutr. 2007;10(2):192-7.

28. Hobbs AJ, Mannion CA, McDonald SW, Brockway M, Tough SC. The impac of caesarean section on breastfeeding initiation, duration and difficulties in the first four months postpartum. BMC Pregnancy Childbirth. 2016;16:90

29. Motee A, Ramasawmy D, Pugo-Gunsam P, Jeewon R. An assessment of the breastfeeding practices and infant feeding pattern among mothers in Mauritius. J Nutr Metab. 2013;2013:243852.

30. Suresh S, Sharma KK, Saksena M, Thukral A, Agarwal R, Vatsa M. Predictors of breastfeeding problems in the first postnatal week and its effect on exclusive breastfeeding rate at six months: experience in a tertiary care centre in northern India. Indian J Public Health. 2014:58(4):270-3.

31. Fenta EH, Yirgu R, Shikur B, Gebreyesus SH. A single $24 \mathrm{~h}$ recall overestimates exclusive breastfeeding practices among infants aged less than six months in rural Ethiopia. Int Breastfeed J. 2017;12:36.

32. Greiner T. Exclusive breastfeeding: measurement and indicators. Int Breastfeed J. 2014:9:18.

\section{Submit your next manuscript to BioMed Central and we will help you at every step:}

- We accept pre-submission inquiries

- Our selector tool helps you to find the most relevant journal

- We provide round the clock customer support

- Convenient online submission

- Thorough peer review

- Inclusion in PubMed and all major indexing services

- Maximum visibility for your research

Submit your manuscript at www.biomedcentral.com/submit

C Biomed Central 